ISSN 2076-0787

www.mdpi.com/journal/humanities

Article

\title{
"Oh, this is What It Feels Like": A Role for the Body in Learning an Evidence-Based Practice
}

\section{Robert Allan ${ }^{1, *}$, Virginia Eatough ${ }^{2}$ and Micahel Ungar ${ }^{3}$}

1 School of Education and Human Development, University of Colorado Denver, Campus Box 106, PO Box 173364, Denver, CO 80217-3364, USA

2 Department of Psychological Sciences at Birkbeck, University of London, Malet Street, London WC1E 7HX, UK; E-Mail: v.eatough@bbk.ac.uk

3 School of Social Work, Dalhousie University, 6420 Coburg Road, PO Box 15000 Halifax, NS B3H 4R2, Canada; E-Mail: Michael.Ungar@Dal.Ca

* Author to whom correspondence should be addressed; E-Mail: robert.allan@ucdenver.edu; Tel.: +1-303-315-4913.

Academic Editors: Sara Horton-Deutsch and Pamela Ironside

Received: 23 September 2015 / Accepted: 19 November 2015 / Published: 27 November 2015

\begin{abstract}
This paper will present research that explored the experiences of couple and family therapists learning about and using an evidence-based practice (EBP). Using a phenomenological approach called Interpretative Phenomenological Analysis, three themes emerged from the participants' experiences: the supports and challenges while learning an EBP, the experience of shame while learning, and the embodiment of a therapy practice. This paper will focus on the theme of embodiment. Research participants' experiences will be reviewed and further explored using Merleau-Ponty's notion of embodiment and Gendlin's (1978) more internally focused understanding of how awareness of a felt sense is experienced as a move "inside of a person". As researchers, educators, administrators, policy makers, and counsellors struggle with what works best with which populations and when, how best to allocate resources, how best to educate and support counsellors, and the complexity of doing research in real-life settings, this research has the potential to contribute to those varied dialogues.
\end{abstract}

Keywords: Interpretative phenomenological analysis; family therapy; couple therapy; evidence-based practice; embodiment 


\section{Introduction}

This paper reports the experience of embodying an evidence-based practice as reported by couple and family therapists learning and using an evidence-based therapeutic approach. Engagement with evidence-based practice is growing across many aspects of the mental health and health care systems [1]. The dialogue about the role of evidence-based approaches in the practice of couple and family therapy (CFT) and its research literature is also evolving [2,3]. Interestingly, while the research delves into what the best approaches are with different populations and presenting issues, little research has explored the experience of therapists themselves, particularly while learning and adopting an evidence-based practice. Using a hermeneutic-phenomenological approach called interpretative phenomenological analysis [4], this research project explored the experiences of 14 couple and family therapists learning and using an evidence-based practice.

The six approaches that research participants discussed were: the Social Ecological Approach [5,6], Attachment-Based Family Therapy [7], Gottman Couples Therapy [8], Imago Relationship Therapy [9], McMaster Approach [10], and Emotionally Focused Therapy [11-13]. Beginning with a general overview of couple and family therapy, the literature reviewed here will then look briefly at evidence-based practices in couple and family therapy. The research literature about the benefits, challenges, and social justice considerations of evidence-based practices was located across mental health fields such as psychology and social work, and to a lesser extent, the CFT literature. Finally, the practice considerations for therapists will also be briefly reviewed. We will then provide a review of the methodology and methods used for this research project then outline the results with a discussion of the same.

\subsection{Couple and Family Therapy}

Couple and family therapy draws from diverse theories and fields, such as: anthropology and cybernetics [14], attachment theory [15], psychology and psychiatry [16-18], circular epistemology [19], sociology [20-22], systems theories [23,24], biology [25], physics [26], communications theory and mathematics [27], and other areas as well. Historically, there have been phases of practice and research in the CFT field that favored particular theorists at different times.

As Hoffman points out, "the family field did not develop in a straight forward fashion from the ideas of [the] early thinkers" ([28], p. 5). The various strands of the history of CFT in North America have been identified as follows: early 20th century social workers who did home visits; couple and family advice offered by religious leaders such as ministers; the child guidance movement that emerged in the 1920s under the leadership of Alfred Adler among others; the formation of the American Association of Marriage and Family Therapy in the 1940s; and the formation of the American Family Therapy Academy in the 1970s [29].

In general, couple or family therapy approach views change in terms of the systems of interaction between members of a couple or family. Sprenkle, Davis, and Lebow explain that "one distinctive common element in all larger systems therapies is conceptualizing human difficulties in relational terms" ([30], p. 35). Problems may originate with an individual, be caused by interactions among family members, or arise from forces external to a couple or family such as a catastrophic event. Each 
couple or family system develops unique operating rules which govern their behavior and life [31]. CFT emphasizes couple and family relationships as an important factor in one's psychological health. The field of couple and family therapy also understands that the structure and dynamics of family relationships are strongly shaped by forces within the broader social context, such as culture, race, gender, politics, sexual orientation, and economics [32].

While the main professional associations use marriage and family therapy to describe the profession and the term "Marriage and Family Therapist" is regulated in every state in the United States, these researchers use the term couple and family therapy. The term couple refers to two partners who have a relationship history together and anticipate a shared future [33]. Our practice and research interests include people who are in a couple relationship, some of whom are married; therefore the term couple is a better fit than marriage for this research project.

The field of couple and family therapy has a rich and diverse history over the last 100 years or so. The research literature began to emerge more fully in the 1950s with a focus on families dealing with schizophrenia and has evolved since then to cover a number of approaches rooted in different paradigms. Part of the more recent history of the field of CFT is the emergence of evidence-based practices (EBP). What follows is a brief review of EBPs including the benefits and challenges of integrating them into the field of CFT.

\subsection{Evidence-Based Practice}

There are a number of considerations to explore when discussing evidence-based practice. To start with, there are the various terms used to describe the research about evidence-based approaches to CFT, such as: empirically supported treatments, evidence-based psychological practices, empirically validated treatment, and principles of empirically supported interventions, among others. For the purpose of this research, we use the term evidence-based practice (EBP) as an umbrella term to encompass a range of CFT approaches developed with the assistance of efficacy and effectiveness research.

The American Psychology Association (APA) took steps to identify what constitutes an EBP in 1995 by defining criteria for empirically validated treatments. These criteria included at least two studies demonstrating efficacy, defined as being superior to a pill or to a psychological placebo or to another treatment, or equivalent to an already established treatment. Alternatively, a large series of smaller studies demonstrating efficacy was also acceptable. For either scenario, experiments had to be conducted with treatment manuals, the characteristics of the research participants had to be clearly specified (i.e., a single diagnosis), and the effects must have been demonstrated by at least two different investigators. The APA also defined "probably efficacious treatments" as two experiments showing that treatment is more effective than a wait-list control group or a larger study or a series of smaller studies meeting all of the previously mentioned criteria except the requirement to have the effects demonstrated by more than one investigator [34].

The field of couple and family therapy research has explored the role of EBPs for practitioners as well as developed EBPs. The proposed guidelines [2] consist of three levels of evidence-based practice ranging from "evidence-informed" to "evidence-based". The three levels are intended to provide "both a hierarchical index of confidence that a treatment model 'works' and a comparative index of clinical applicability" ([2], p. 382). Interestingly, Sexton et al. [2] suggest that evidence should include at least 
two outcome studies with research coming from multiple sites and go on to indicate that to be evidence-based, couple or family interventions should include: clear specification of the treatment model, clear identification of the client problems, the use of valid measures of clinical outcomes, and other criteria. These criteria are very similar to the APA guidelines released in 1995, and while suggesting elsewhere that there are contextual factors that are important to attend to, they do not attend to how EBPs can design research to attend to these factors. The next section will focus on the benefits, challenges, and social justice considerations for CFT practitioners and researchers.

There is a sense of hope about the possibilities for EBPs in the development of the field [35], both for the people receiving a service as well as for practitioners and researchers who can increasingly feel confident that their work is supported by research. There are a number of benefits of EBPs for CFTs starting with the research conducted to determine whether an intervention is likely to work with a given disorder [36]. Clinicians have a clinical, ethical, and legal responsibility to attend to the results of RCTs [37,38]. Developing evidence-based CFT practices is seen as a natural progression and evolution of the field, a maturing of sorts from anecdotal clinical reports to "conceptual and methodological sophistication" of CFT research and clinical practices [39]. For program managers, funders, and government departments, there is an increased pressure to allocate resources on an explicit rational basis and in consideration of consumer rights, which again means attending to the results of research [40,41]. The culture of EBP is intended to have a heuristic value [42] and while there are a number of benefits of evidence-based research for therapists to consider, there are other perspectives that enrich the dialogue about evidence-based approaches.

These other perspectives challenge the focus on EBP and how the research is done as well as raise social justice considerations for therapists. The narrow epistemic band that informs the research approaches used to establish an EBP is one area that has been consistently critiqued [43-45]. Other questions raised in the research literature about EBPs include: the lack of inclusion of practice-based expertise and service users' values [46,47], the differences with therapy in real-life [48], that EBPs promote a view of decision making that is deterministic [49], the danger of relying on EBPs only [50], and the potential to make third-party payers de facto untrained supervisors [51].

The social justice aspects of the evidence-based dialogue include the political, social, and economic functions and interests of professional associations and social control functions these associations engage in [52]. One of the more troubling aspects of the empirically supported treatment enterprise is the "systematic discrimination against certain classes of research, treatment, and patients" ([42], p. 118), in particular, non-English research, qualitative research, research with ethnic minorities and children. CFT practice cannot be guided by research findings alone; it relies on multiple values, tacit judgement, local knowledge, and a range of skills [53]. This contrasts the notion of the clinician as "an institutional subject who is presumed both to know the truth of disease and to have the moral and intellectual authority to prescribe treatment" ([54], p. 183).

The hope expressed in the literature is that EBPs have the potential to be externally valid, can include qualitative components to add richness and relevance, and can be used to study common factors. Many of the problems noted with the related research are how they are used and misinterpreted to make claims that are too far reaching [30,55]. EBPs present a range of benefits, challenges, and social justice considerations for CFTs and researchers alike. The next section explores the terms and different meaning of embodiment and the psychologically oriented term embodied learning. 


\subsection{Embodiment and Embodied Learning}

There is a tension in the research literature between a phenomenological approach to embodiment and the psychological approach of embodied learning (for a full exploration see [56]). In short, the tension reflects the Cartesian division between the individual knower (mind) and what can be reliably known through sense experience (body) [56]. The interpretative choice here is to privilege Merleau-Ponty's phenomenological understanding of embodiment because such an approach suggests there is no longer an epistemological division between subject and object; the world is experienced though a "phenomenal body" and participants interviews' are explored via their experiences of embodiment [57]. The participants in this research project discussed a process where they felt like they were moving towards something in their training that was deep inside them. As Finlay noted, we mostly "live our body-world interconnections pre-reflectively, without thought with the body having its own wisdom and memory" ([58], p. 31) [bolded word in original text]. The participants discussed a felt sense of grappling with learning a new approach to working with couples and families. For most participants they were on a quest to become more effective in their work with couples and families and were surprised how much personal work was involved and how much it had to do with something "in" them. Some participants identified it as a "part" or a "piece" inside them while others discussed a "feeling" or described a felt sense they had when they struggled or experienced success at integrating an aspect of a new therapy approach they were learning with their clients.

The research participants were not asked about bodily feelings; for us, this emerged from the data and reflects another interpretive decision that we made. Drawing on Merleau-Ponty's [59] writing that we all have a "view from somewhere", the body came to the fore as we were analyzing participant data. Here, we are not referring to "embodied cognition" which is based on the idea that our representations of learning events often involve somatosensory re-experiencing of the relevant event in one's self [60]. Our decision is to reflect Merleau-Ponty's notion that we are our body not that we have a body [61]. Further, none of the participants offered an experience such as "my thoughts were confused" or "I struggled with the different ideas" coming from their experience of learning an EBP. Nor did they preface experiences of "tension" as emanating from conflicting ideas or competing cognitive processes. Also, exploring embodiment is not just about the physical body but also about felt sense. As Finlay wrote, "Phenomenological researchers aim to tap into the insight that our bodies are in continuous relation with the world by focusing explicitly on the kinaesthetic, sensory, visceral and 'felt sense' dimension of bodily lived experience" ([62], p. 30) [bolded word in original text]. Turning to the research process, the next section introduces the methodology and methods used for this research project followed by a review and discussion of the results.

\section{Methodology}

The methodology relies on a phenomenological framework, specifically interpretative phenomenological analysis (IPA) [4], and is therefore interested in the experiences of the therapists themselves and the meanings they attribute to these experiences. IPA draws on ideas from phenomenology and hermeneutics, specifically a double hermeneutic where the researcher makes meaning of the participant's meaning making process. IPA is most influenced by the Heideggerian 
interest in exploring the phenomena of the interpreted world. At the same time, IPA calls for the researcher to engage a hermeneutic of suspicion [63] by using theoretical perspectives from outside to shed light on the phenomena. From an IPA perspective, experience is always constructed and enacted through a variety of mechanisms. It is therefore critical that discussion of the research design acknowledges the relations between the experiences of therapists and their interpretations; theory and experiences; methodologies and methods with the hope of engaging the reflections of significant events of the research participants [4].

Data were collected through interviews with therapists guided by semi-structured questions that were sufficiently flexible to allow participants to discuss their experiences in-depth related to the topic of the study. As recommended by proponents of the methodology, questions were "prepared so that they [were] open and expansive; the participant...[was] encouraged to talk at length" ([4], p. 59). Sample questions included: Can you tell me about how you became a couple/family therapist?; Can you tell me about a CFT evidence-based approach that you have learned about?; What influenced your decision to learn about that CFT approach?; Can you tell me about what you enjoyed/ found challenging about learning that new CFT approach?; Who supported you?; How did you deal with challenges in learning that new approach?; Did your work place provide support?; Are there clients with whom the EBP does not work?; and How does culture, context, and resources play a role in the effectiveness of an EBP? The interviews lasted 60-100 min. and were audio-recorded and transcribed verbatim and further reviewed by the first author to capture the specific text of the interview as well as the intonation, utterance, and other components of speech which may lend itself to further interpretation.

\subsection{Participants}

Fourteen therapists aged 32 to 65 were interviewed by the first author. This is a substantial sample size for an IPA research project. In part this is because of the commitment in IPA "to a detailed interpretative account of the cases included and many researchers are recognizing that this can only realistically be done on a very small sample" ([4], p. 56). Criteria for inclusion were therapists who have at least a Master's degree in a mental health field such as counseling, psychology, social work, or marriage and family therapy. These professions were targeted for interviews because it is these professionals that are recognized as offering couple and family therapy. Participants had to be, or had been, actively engaged in learning about and using an evidence-based couple or family therapy practice that included a treatment manual, they had received training and supervision specific to that practice, and the EBP they were learning had a theory of change that therapists were required to relate their practice to. Participants had one to 42 years of post-Masters' clinical experience. In terms of professions, there were five Marriage and Family Therapists, three Counselors, three Social Workers, two psychologists, and one psychiatrist.

\subsection{Data Collection}

The study was granted ethical approval by the university and individual interviews with the therapists occurred either face-to-face or via Blackboard Collaborate. BlackBoard Collaborate is an on-line learning software system used by the university that provided ethical approval. Among other functions, one can conduct, record, and save an interview in this system. The research was completed 
at a Canadian university and BlackBoard is hosted in a Canadian city and was not directly exposed to the effects of the USA PATRIOT Act. Also, using BlackBoard satisfied the university's policy Protection of Personal Information from Access Outside Canada. Participants were recruited via professional listservs, snowball sampling, email, and direct requests from the research team.

\subsection{Analysis}

The inductive procedures of IPA are “intended to help the researcher to develop an initial insider's perspective on the topic" ([64], p. 22). This flexible technique allows the researcher to identify unanticipated topics or themes during analyses. The role of an IPA researcher is not to verify or deny a hypothesis but to develop broader research questions which lead to the collection of expansive data. "The orientation of researchers towards these objects of interest (experiences, understandings) is generally open and often explicitly process-oriented" ([4], p. 46). Understanding is attained by describing lived experiences and the meanings that emerge from them.

In general, IPA moves from the particular to the shared, from the descriptive to the interpretive, it maintains a commitment to understanding the participant's point of view, and has a psychological focus on personal meaning making in particular contexts. Smith, Flowers, and Larkin (2009) outline a six-step process for the analytical process which we used in this research. These six steps included first reading and re-reading the transcripts and noting anything of interest. Next was initial noting of the participant's content, linguistic interpretations, and conceptual comments. In the third step we developed emergent themes followed by the fourth step where we searched for connections across emergent themes and identified the purpose a theme may play in a therapist's life. For the fifth step we moved to the next case and repeated the same analytical process. The sixth and final step was to begin to look for patterns across transcripts and identify the most important things to say about participants.

Practically, we used MS Word and created a box with five columns. The first column numbered the passages in the transcript, the second column had the transcript of the interview, the third column had initial noting at three levels about the participant's content, linguistic interpretations, and conceptual comments, the fourth column had the emergent themes, and the fifth column the super-ordinate themes. The initial noting in the third column included descriptive comments in normal text which are comments that focused on describing the content of what participant has said or the subject of the talk within the transcript; linguistic comments were italicized and focused on exploring the specific use of language by the participant; finally, conceptual comments were underlined with a focus on engaging at a more interrogative and conceptual level. These comments were made directly in line with the place they appear in the transcript so that one could read across and when that was not possible, we color coded the comments to link them with the places in the transcript that were being commented on.

What follows is a review of a major theme that emerged from analysis of the participants' experiences with learning an EBP, that of embodying a therapeutic practice. This review includes passages from the interviews and participants were given pseudonyms to protect their identity. While the participants' experiences are foregrounded in this review reflecting a hermeneutic of empathy we also bring in theory to further explore these experiences reflecting a hermeneutic of suspicion [63]. The latter is consistent with IPA given the priority placed on participants' own experiences and words. 


\section{Results}

We will first describe the participants' experiences in relation to integrating a new therapy approach. This integration will then be further explored using the writings of Merleau-Ponty (2005), specifically his notion of embodiment, and Gendlin's (1978) understanding of how that process can happen with something he calls focusing. Here the body will be considered as "a form of consciousness" ([59], p. 62) and a means to experience the world and start to make sense of it. In fact, that it is not possible to make sense of an experience without one's body. As Merleau-Ponty writes "The body is our general medium for having a world. Sometimes it is restricted to the actions necessary for the conservation of life, and accordingly it posits around us a biological world; at other times, elaborating upon these primary actions and moving from their literal to a figurative meaning, it manifests through them a core of new significance" ([57], p. 169). Gendlin on the other hand offers a means to understand what that process looks like in more detail and described focusing as "a process in which you make contact with a special kind of internal bodily awareness" ([65], p. 10). He refers to this awareness as a felt sense where the focus is a move "inside of a person" [65] (p. 21). While Merleau-Ponty offers an epistemological means for situating the body as pre-reflective, Gendlin writes of a praxis to explore the process of embodiment.

We have chosen to organize the participants' experiences with the assistance of Gendlin's six movements for facilitating focusing which he described as: clearing a space, felt sense, getting a handle, resonating, asking, and receiving. The interpretive choice to describe them loosely using Gendlin's six movements emerged with the data as we were organizing the participants' experiences. This interpretive selection also facilitates further discussion of the participants' experiences at the end of the paper. While all 14 participants discussed some aspect of embodying an EBP, nine of the participants were identified as having discussed it with some depth. We have included samples from six of the participants here largely for practical purposes and to restrain the length of the paper.

One example of a participant discussing embodiment is Ken who reported his experience of feeling like he had reached Everest at a point in his learning; we imagined the physical exertion it took to get there. Another example came from Louise as she discussed a major life event that influenced her choice about which EBP to learn, that of adopting her four year old niece, "because I saw so viscerally what that does in terms of the four year old, my four year old daughter right, I saw how different her world looked when she was securely attached, and what a different experience of the world she's going to be and what a different gift to the world she's going to be because she's known secure attachment".

Louise saw "viscerally", of or pertaining to the viscera which are the internal organs in the main cavities of the body, especially the abdomen [66]. Further in the interview with Louise when she described the role that reading played in her learning an EBP, we imagined how the reading impacted her "viscerally" because that is the foundation that she laid for her understanding of the EBP she was learning. Another example from the participants that influenced our interpretive turn towards embodiment came from Raylene. As she discussed a key point in a supervision session that lead to an important revelation that assisted her learning of an EBP, she reflected that "in that moment, I had this like experience in my body, where I, it's like this pain going into my gut". The pain going into her "gut" came in the midst of a clinical supervision session focused on the EBP we discussed during her interview. As an important revelation about a block in her learning came to light, as Raylene was 
learning the EBP, and as she reflected back about what a key in her learning that was, she described it as "going into my gut", as if entering her body. Each of the examples from Ken, Louise, and Raylene, as well as passages from other participants, led us to further explore the experience of embodiment while learning an EBP. As Matthews noted, "to be embodied means that living in the world comes before conscious thought about the world" ([67], p. 56), experience is pre-reflective. Now, as Husserl [61] would suggest, to the participants' experiences.

\section{1. “So O.K., Let's See What This is about”: Clearing a Space for a Felt Sense}

This aspect of Gendlin's model encompasses two phases, that of clearing a space and developing a felt sense for the problem. The former was described by Gendlin as listing "the problems mentally...the major and trivial together" ([65], p. 52), not focusing on any one in particular. The latter, developing a felt sense for the problem, is a focus on the most challenging aspects of an experience and developing a sense of "how it makes you feel in your body when you think of it as a whole" ([65], p. 53). The driver for most participants in this research was to become more effective at working with couples and families. Ken summarized it as not about specific clinical issues but "I think just more the issue about how generally, how to be more effective as a marital therapist, couples therapist, relationship therapist". Interestingly, across all professions-social work, counselling, psychology, and marriage and family therapy- none of the participants felt like their graduate studies prepared them to adequately work with couples and families.

Cassandra for example, a licensed marriage and family therapist in the United States, mentioned that she "didn't feel like [her] master's level course, it was just one course, and quite honestly it wasn't the greatest course in the world, and [she] didn't really feel like it prepared [her] to see couples". While Kathy, a registered social worker in Canada, described starting her private practice over 10 years into her career and the struggles she had working with couples; she reported that "like a lot of therapists, [she had] worked with couples but [she had] never felt successful with them". This lack of success impacted Kathy's experience of her work with couples as she discussed how she "never really enjoyed working with them". A major contributing factor to her lack of joy was her sense of a lack of efficacy describing how she "didn't feel [she] knew what to do and you know you get a couple, you don't know what to do and you see them individually". Like Ken, Cassandra, and other research participants, Kathy wanted to experience herself as effective in her work with couples stating that "[she thought] if you're doing a job, you want to feel that you have something to offer, and [she] didn't think [she] really had a frame of reference to operate in". An important reflection for research participants such as Ken, Cassandra, and Kathy was to recognize that they did not know what they were doing and clear a space for new learning. What emerged from that initial desire to be effective, however, was a surprising process for the research participants.

Louise, for example, discussed her experience with adopting her niece as one that affected the direction of her therapy practice when she returned to it after taking a few years off to focus on her family. Living with and integrating a child into her family who had had a series of dysregulating experiences during the first few years of her life exposed Louise to the importance and complexity of secure attachment. These experiences gave her a felt sense of the importance of attachment, as Louise described, "because [she had] lived it. And [she saw] how powerful it is". For Louise, the space in her 
for this felt sense to emerge was cleared by the experience with her niece. This new felt sense led her to seek further training and supervision in an approach to working with couples that integrates attachment theory. Her work became infused with a purpose and direction informed by the experiences with her niece and a desire for her work to be effective on a number of levels. She described it as follows: "Ah, because at the end of the day that's probably the primal theme, so it makes me ah, it's very meaningful for me, and like I said I really feel like oh my God I'm getting in there, the rubber's hitting the road, I'm doing something, I am changing the world you know because if at the end of the day someone feels more securely attached, the world's a better place, right you know."

Louise discussed the space cleared as moving her to work with a "primal theme". Primal is defined as first or most important [68] and Louise described her work as fundamental to survival the way one would describe water or food. Her experience and her work now focuses on working with the body at a basic sustenance level. Louise's approach evokes the research of Harlow and Zimmerman [69] commonly known as "Harlow's monkeys" where the behavioral hypothesis that an infant would form an attachment with a carer who provided food was disproven. For Louise the part of the training that focused on attachment "just spoke to [her]" evoking the felt sense aspect of embodiment that Finlay [58] noted.

This sense of having a part of oneself spoken to was shared by other participants. Jessica for example, felt "drawn" to her training in a new EBP in a way that "spoke to [her]". Her knowledge of attachment theory lead her to seek further training, as she said "so o.k., let's see what this is about". As she described, "I was really drawn to that whole idea of that's how, how people, how you can explain, how things can get distressed in life, so that started that part of it". She went on to describe developing a new "lens" as if she had new eyes now looking at the couples and families she was working with saying that "it just seemed to really gel and really come together for me as a way of this is how things can get so off track". While describing her struggles with integrating the new EBP into her practice, Jessica also felt moved in a way she had not experienced in her prior learning, as if she was wrestling with the new therapy model. She described that "there's something quite compelling about the model that kind of keeps pushing and I never felt it before". Being "pushed" by a therapy model in a way that she has not "felt" before suggests a physical sensation. As if Jessica was describing an invisible set of hands moving her body in ways she had not experienced before.

This pre-reflective push may relate to another aspect of embodying a new therapy practice, what Gendlin would describe as "finding a handle" or the "core of the felt sense" ([65], p. 55). For some of the participants in this research project, their own lives became a key means they found for learning more about a new therapeutic approach and embodying the practice. This was true for Jessica as she described “...but in any other learning that I've done or in theory or, I don't think I applied it so directly to my own life". What follows is a further exploration of a means that participants had for learning a new approach to working with couples and families by embodying it into their own relationships and families.

\section{2. "My Personal Life has been Deeply, Deeply, Deeply Impacted": Getting a Handle}

Gendlin [65] wrote that the key in this phase is developing a sense of the quality of the felt sense. For the research participants who described a tremendous sense of growth, personal fulfillment, or 
development in their therapy practice and as people, there was a certain kind of active engagement with the learning process. They found themselves, their relationships, and their lives as an integral source for learning. Raylene summarized getting a handle by mentioning the improvement in her therapy work, "but not just my clinical work. My personal life has been deeply, deeply, deeply impacted. It's impacted my relationship with my husband, my relationship with my children, my relationship with my friends..." This learning process was not always an easy one though it was compelling for some participants.

Jessica for example described the impact of the training on her work with couples and families by mentioning that "there's something that's deeper in this [EBP] and that's what keeps [her] coming back". The mention that it is "deeper" suggests a sense that her learning is more embodied, going further into her bones and sinew as if it is a feeling that cannot be ignored. She went on excitedly to describe a new experience in her work with couples and families where individuals were able to name their experience and communicate it to each other in a way that facilitated their therapeutic goals. For Jessica this keeps her coming back to the learning about the EBP she was integrating into her practice and she mentioned "because [she thinks] when you can see that...you can't shy away from it so you have to continue and you have to, in some way, go with that, so that's what keeps [her] coming back". One way of understanding her description is to use Gendlin's (1978) notion of getting a handle; Jessica is facilitating that process with the couples and families she is working with. At the same time, she has a "deeper" experience herself that provides her a handle for understanding what she is exploring in her training. This naming or getting a handle for Jessica is different from her previous clinical work and training, she described that she had not "felt that way in session in any other way". This kind of unique experience that was compelling for some of the research participants here also presented others with challenges.

Ken was one participant who described some of the struggles he experienced deep into his learning a new approach to working with couples. He described how it "certainly has been harder for [him] to not go into that inner critic and think 'I'm really stupid enough and I should really stop doing this and take on, you know become a plumber". Ken's "inner" critic questioned his ability to learn a new approach 42 years into his practice and one that had him learning over the years with some of the leading figures of couple and family therapy. For Ken, the experience of embodying a practice ultimately lead to some of the most exciting moments in his clinical work which will be described later in this paper. That process, however, came with experiences of pain "in" him that were unavoidable.

As Raylene noted about learning Emotionally Focused Therapy (EFT), "you have to understand attachment in your own being and then make sense of it cognitively. But you have to really understand and get it, so it's not an easy approach to learn, to really get good at it". While convinced that you have to understand it "in your own being", Raylene also notes that this makes it more challenging. She goes on to punctuate the importance of knowing in our bodies by saying that "it has to do with having the inner experience internally so that you get the experience from the inside out". Raylene suggests that EFT must first be known by the body to be able to practice it effectively. The knowing is "inside out", first in one's body then in one's head, and on to the application of it. Raylene has enough experience with that process to be confident that her integration of EFT is "going to continue to unfold, [she knows] where [she is] going". Part of her experience included another aspect of embodying a practice, 
that of resonating with a felt sense or handle that is uncovered. What follows is a description of the research participants' experiences with this aspect of embodying a practice.

\section{3. "I had No Idea What I was Getting Myself into": Resonating}

Resonating, according to Gendlin (1978), is the process of checking the quality of word(s) developed from the third phase (getting a handle) against the felt sense. Many participants found the challenges of learning an EBP left them reflective on the one hand and angry on the other. Raylene, for example, mentioned that while first learning EFT, "I was going through a divorce of a 20-year marriage and so it was actually helpful for me, it was kind of ah-ha for me when I experienced just the whole approach of EFT". Here again, the first thing she related the learning to was the body of her recently ended marriage. Raylene related her new learning about the EBP we discussed to her own lived experience and recently ended marriage and it resonated for her in an "ah-ha" moment. For others, they were left reflecting about the complexity of their clinical work that the EBP they were learning was not able to address. George addressed it by saying “...you know we had all these smart therapists that were coming in and doing these trick therapies and we were shaking our heads in a way and saying but that's fine, these guys have no respect for the stickiness of change and you know they seemed, it's a bit car salesman approach to therapy."

Both George and Raylene describe resonating with their learning, finding a fit between a felt sense and the words to describe that experience. For Raylene it gave her the opportunity to begin to name a felt sense about her recently ended marriage that had remained unsettled for her. While for George, he felt like he was being manipulated in some way or sold something at too high a price or something he did not need. George noted this manipulation by mentioning the "stickiness of change", a tactile way to describe a feeling that he experienced in the room with the families that he has worked with. Another way that George might convey that feeling might be by saying "but these guys have no idea what it's like to be embodied in the room with the families that I work with".

Resonating with a felt sense was described by the research participants here in both an exuberant manner and as a way that they were challenged to embody the work. Raylene summarized it well when she said "I thought...that I was just going to become a better therapist this year...I had no idea what I was getting myself into. I had no idea that it was going to transform me in such a deep and profound way and transform really my world view in such a positive way." For Raylene, being changed in a "deep" way was a positive experience with her "view" changed. Again, the experience is "deep" in her and it is not her "thoughts" that changed or her "skills" but the way she sees has been changed as if seeing with new eyes. Exploring this part of embodying a new approach to working with couples and families with the research participants lead to their discussing two interesting aspects of learning an EBP; the challenges with learning and the challenges of the EBP project.

The challenge of committing to fully integrating a new approach into one's practice was noted by all of the participants who went on to become recognized as having a level of proficiency in the approach they were learning. This proficiency was usually recognized with certification by a professional body that could assess the competency in a specific approach to working with couples or families. Ken for example, reported his experience of becoming a certified EFT therapist as follows: "it is by far the most difficult training and learning process that I've ever been in, and I've been a 
therapist for 42 years and it was, it was astounding". While Gendlin described resonating in a manner that suggests it may take minutes to get a "fit...that the words are right" ([65], p. 56), for the research participants here that sometimes took months or even years. As if they were stuck in the middle of their body flailing about, drawn on the one hand by a felt sense they felt was "positive" and "deep" inside them while on the other recognizing that they could not identify what was there.

Jessica for example described that sense of what drew her further into her learning. She mentioned being able to "relate so directly to some of the, if you get into the details around what the EFT looks like, especially around those messages that we carried from childhood and into adulthood, into relationships. [She got] it, you know, on a different level because they resonate, some of those messages resonate with [her]." The "message" of the learning for Jessica resonated with her own lived experience. The resonating she reported was not with a theory of how to work with couples; she resonated "on a different level" because the "messages" resonate with her own lived experience. She goes on to mention that to "be able to see it that way...not just from oh 'I can hear it from a client, I can hear what their experiences are', but [she] also, can relate well, ...not to every experience, but [she got] it". Jessica's experience of resonating with her learning about a new approach and embodying the practice shifts her experience with clients to where she can "get it". This felt sense that Jessica describes with her clients where she can "get it" means she finds a fit between that felt sense and what she hears from or does with her clients.

Integrating a new therapy approach is not always an easy process. As Kathy so aptly puts it: "when you're first learning it it's sort of you know, you're not sure but you're sort of on shaky wheels, you're not sure where things fit in". Focusing on how things "fit" is a key aspect of embodying a practice and the second interesting aspect of that process in relation to EBPs that research participants noted was the challenge of the EBP project. Ken for example addressed this challenge by saying that he thought "there's a lot of resentment around the fact that [they have] got to be 'scientists' when [they are] actually artists so to speak". Ken invokes the sterile clinical image of a "scientist" in opposition to that of an artist. Oxford Dictionaries define a scientist as "a person who is studying or has expert knowledge" [70] and an artist as "a person skilled at a particular task or occupation" [71]. As if one may be a scientist on his or her way to becoming an artist or that a scientist may have knowledge about therapy but not actually know how to do it whereas an artist does know how to be a therapist. For some of the participants in this research project, a focus on EBP was a barrier to becoming an artist and to embodying a practice.

One of the participants, George, spoke at length about the challenges he had with evidence-based practices. As an experienced family therapist, George has participated in a wide variety of training over the years though he still referred back to his early experience with adapting the McMaster Family Assessment Device as the foundation of his understanding for working with families. This seminal experience also shaped his understanding of what can happen when there is too strong a focus on one approach to working with families. He described an experience where he and a few colleagues fully engaged in learning a new approach to working with families while others were more hesitant as follows: "So there was this tension... where it should be in the whole scheme of things, and so there was this, not always healthy, dialogue going on between us, who would see everybody else as antiquated, and the others, who would see it as you know blind to this new drug we were just high on..." George situated his description in the body describing a "tension" and the "new drug we were 
just high on" describing a felt sense of euphoria when they found something that fit for he and some of his colleagues while others struggled with those embodying a practice. The struggle George described sounded like a team sport game where the two sides competed for "where it should be in the whole scheme of things". On one side were a team high on "this new drug", on the other side the "antiquated" athletes.

George went on to describe some of the challenges he experienced with EBPs over the years. Like other research participants, he too described a sense of how there is a calling or something in a person that drives them to continue to engage in the process of integrating a new practice. George, however, had a different take on this experience. He described it as having a rigidity stating that, "there was a religious kind of sense in which these therapies are imbued, they have a certain kind of inclusive/exclusive kind of quality to them". For George, part of what is missing in the EBP project "is a huge amount of human experience" that he feels "is not captured in evidence-based practice". For George, the urging that some experience while learning an EBP takes him away from "human experience". George goes on to describe how he does not "think we should be ...kind of blind, it gets a little bit like a God that you have to obey and [he does not] want to go down that route". He continues to describe the challenge he experiences with EBPs in terms of what his body will do and where his body will go or not go. George qualifies his engagement with EBPs by stating that: "I want to listen to that piece but I don't want to let it dictate my life". George comes to a clear understanding of how he wants to embody a practice that does not fit for him. He can hear it, he'll resonate with what he describes as human experience, and decide what "route" to go down.

The participants in this research project described a range of experiences when resonating with a felt sense or something "in" them or as the training "deepened" and all described some part of how they resonated. For some, it was about how the practice they were learning did not fit for them or they could not find a way to make sense of their felt sense. Some of the participants however went on to describe what Gendlin (1978) described as a body shift. This shift left them with a tremendous sense of accomplishment and a feeling like they had integrated the therapy approach they were learning at a new level.

\section{4. "Something has Shifted inside of my Body": Asking and Receiving}

The fifth and sixth movements in focusing are asking and receiving. Gendlin writes that asking involves "spending some time...staying with the unclear felt sense, or returning to it again and again" ([65], p. 58). Receiving involves welcoming "anything that comes with a body shift...not in it, but next to it" ([65], p. 61). One can receive without asking, a shift can happen in the body that one can link with a description without asking. The kind of embodiment that people experience when the learning that they do is "deeper" translated into how they experienced the interview as well. As Raylene noted "you know even if I'm sitting here talking to you, I mean I feel completely comfortable being totally transparent with you. Something has shifted inside of my body". The "shift" that Raylene experienced "inside" her body came in the process of her learning about EFT and as noted earlier "deeply, deeply, deeply" impacted her personal life. That shift inside her body not only impacted her personal life however as she noted that it also "greatly affected all of [her] clinical practice" and she went to say that "yes all of [her] clinical work has been deeply, deeply, deeply, deeply impacted". 
Raylene was able translate that "shift inside" her body across personal and professional contexts as well as the interview that I did with her. Finlay (2005) noted that this awareness of embodiment in the interview context reflects an awareness of the intersubjective bodily relationship between participant and researcher [62]. The kind of delight that Raylene experienced with this kind of embodiment was shared by other participants in this research project.

Ken may have been one of the more exuberant research participants when he described a feeling of reaching "Everest on this issue" when describing his experience of a moment in therapy where his intervention was effective and was a strong demonstration of the approach he was learning. After months of struggling with a new approach to working with couples, Ken described how "it was gratifying to say the least to, in that moment to see oh yes, my god I've got it. Now [he understood] all of the teaching and the training you know that [he had] been given". He went on to describe his sense of climbing while learning as if every part of his body was involved in the process: "It's just at a new level but there's something very contenting, exciting, something that is very, it makes all of the struggles so worthwhile in that moment because it's like I've reached a level of knowledge, of wisdom that is, all come together, so something like that."

As Ken described this process, one can imagine him panting at the top of a summit, every part of his body aching and heaving with a combination of excitement and exhaustion with the realization that he had accomplished a long fought for and dreamt of goal. Every ledge he had clung to and every choice point about where to go next suddenly realized in a moment of success where he now had the expanse to see what he had accomplished. It was Ken's movement towards understanding "all of the teaching and training" that left an impression for us as researchers.

Louise was another research participant who delighted in her newfound experience of the "power" of her work after integrating a new approach to working with couples. Her delight was more of a surprise to her, however, as she described, “...it's kind of blowing me away because [she got] a lot of really positive feedback". Here again, we interpret Louise's description as a state of motion where she's impressed, as in her body is moved by the experience. She went on to describe that "it's kind of blowing me away and I know it's because this is the way we work with people right, I know that, I know that". While being blown away, or moved, Louise also recognized that she has become part of the therapeutic change process she had worked so hard to learn about. Louise went on to describe the depth that she received this shift she experienced when being "blown away" with her work.

For Louise being "blown away" meant finding who she was as a therapist. She described "it's how I work with people and I've been so grateful cause it's given me, like I said, it's given me this I now know who I am as a therapist" going on to say that "right, this is what I do". Louise contrasted that with her training in graduate school where she was introduced to "many different approaches there are out there" which left her questioning her identity as a therapist. Learning an EBP gave her a "map" which she described as giving her "a little bit of a sense of o.k. [she felt] like [she knew, she was] on a road and [she felt] like [she was] going somewhere". For Louise, learning an EBP gave her both an emotional reaction ("a feel") and a sense of direction (a sense of "going somewhere"). Not only does she now "feel" herself as a different therapist but she also experiences her whole body as moving in a direction that reflected how she felt. For the research participants who described an experience of embodying a practice, they found that process crossing over in to other aspects of their lives. 
Ken spoke of a new feeling describing that he felt much more confident, more "than I ever have been". Ken's new felt sense of assurance emerged in other contexts outside of a therapy room as if he could not stop his body from doing anything different. He went on to describe: "when I'm not confident I can speak about that, I don't hide that as much as I used to. And I don't hide it very much anymore at all". Ken's description of not "hiding" this new felt sense as if a disfigurement he had previously covered up translated into a new significance that he described as "opening [himself] and allowing [himself] to really, just allow people in at a new level, at a much deeper level". Ken repeats the refrain shared by other research participants who experience themselves and others with a "deeper" felt sense and often elaborating their description with reference to a physical sense. Ken went on to describe how "it's no different than the child who looks at the candy is one thing but when you get to taste the candy, wow".

Ken offers a mouth-watering distinction between savoring the taste of candy longed for in the excited manner of a child and simply looking at the candy. This wide-eyed description gives a strong flavor of receiving a new felt sense that he not only looks at but literally internalizes. This embodied notion of experiencing the world from somewhere, specifically from our bodies, links to Merleau-Ponty's (2005) understanding of embodiment. Moran clarifies the distinction by noting that it is not that we have a body but that "I am my body" ([61], p. 406). What follows is a brief exploration of Merleau-Ponty and Gendlin's writing about embodiment in relation to the experiences of the participants in this research project.

\section{Discussion}

The research participants did not separate their bodies from what or how they were learning. They reflected Merleau-Ponty's notion of the body as standing "before the world and the world upright before it, and between them there is a relation that is one of embrace" ([72], p. 271). This pre-reflective stance where the body drifts into the background becoming part of the horizon we take for granted is how we most often experience our bodies. Like Raylene's mention that at the start of her learning EFT, the changes she later reflected in her work were not "even conscious at the time". It was only in reflecting about the questions that we asked that Raylene could talk about what had happened "inside of [her]". For therapists, there is an importance for embodied learning that translates to the work with couples and families. Churchhill, Lowery, McNally, and Rao [73] write about how the body enables us to understand the Other empathically and therefore to listen fully to their experiences.

The full listening that the body contributes to posits the body as a form of consciousness. As previously noted, Merleau-Ponty argues "that the body cannot be thought of as a mere object. Instead, it is a subject: a form of consciousness" ([59], p. 62). While Merleau-Ponty offers the opportunity to explore the participants' experiences from the position of the body, Gendlin positions the body as the place where change is felt and processed. He writes that "there is a distinct physical sensation of change, which you recognize once you experience it" ([65], p. 7). Merleau-Ponty writes of a body interacting with, impinging on, and being compelled to act by the environment while Gendlin goes into the body, describing what happens when those interactions take place. Both start with an understanding that not all learning can take place with the use of rationality only. Finlay writes that perception for Merleau-Ponty, "is inherently participatory — an active interplay between the perceiving 
body and what it perceives, and between the doing body and what it does. There is a mutual relation between the self, body, and world" ([58], p. 36). Such a perception cannot rely on cognition alone nor a mind in isolation from the body or a mind that dictates to the body. As Finlay noted, "It is impossible to separate our bodies from who we are and what we do in the world. Our body is the vehicle for experiencing, doing, being, and becoming" ([58], p. 29). From this perspective, we go "to the body" as a means to understand participants experiences with learning an EBP beginning with, as Gendlin suggests, clearing a space for a felt sense.

Clearing a space for learning a new EBP from a rationalist's perspective may focus on how much a person needs to study, read, or focus his or her intention on learning a new approach to working with couples or families. Merleau-Ponty [57] used the example of a man, by the name of Schneider, with an acquired brain injury to explain the limits of this approach. When asked to raise his arm by a psychologist, because of the area of his brain injury, he could not raise his arm. Schneider worked and otherwise maintained much of his life as he had before the injury and was physically capable of raising his arm and intellectually understood the request. Merleau-Ponty used this example to outline three limitations of a focus on intent: one, it does not explain why it is only abstract actions that create difficulties; secondly, Schneider's intelligence was otherwise intact and it was not a matter of his inability to rationalize; third, it was not a matter of not having the thought to do something. To assist with understanding the limitations of a focus on intent, Merleau-Ponty makes the distinction between concrete and abstract actions. He writes that abstract actions are not, "relevant to an actual situation" ([57], p. 118) or "movements, that is, which are not relevant to any actual situation" ([57], p. 118). Merleau-Ponty goes on to note that "concrete movements and acts of grasping therefore enjoy a privileged position for which we need to find some explanation." ([57], p. 118). For the research participants in this research project, they experienced the discord that actions that are abstract to their bodies impose. As Kathy noted prior to her learning an evidence-based approach to working with couples: "I've worked with couples but I've never felt successful with them. Never really enjoyed working with them, I didn't feel I knew what to do and... [would] you see them individually." Kathy described how she returned to what, for her, were concrete actions. Prior to learning the EBP we discussed, Kathy would simply do what she knew how to do, see the couples she was working with individually. In therapy with couples, the focus of the work is the relationship, not individuals. With a few exceptions (e.g., abuse) it is counter-productive to work with a couple by seeing them individually. That would be akin to diagnosing a cold because you hear a cough and never examining the lungs to understand that it is cancer. Despite this challenge, Kathy found herself seeking a clearing, following her felt sense of wanting to find a way to work with couples differently.

This clearing was reflected by the research participants in this research project in two ways. First, with their intent to be more effective with couples or families, the research participants accepted that they had something to learn. Secondly, they found something that spoke to a "part" of them. Gendlin writes that "a felt sense is usually not just there, it must form" ([65], p. 10). This forming takes place "by attending inside your body. By certain steps it can come into focus and also change. A felt sense is the body's sense of a particular problem or situation" ([65], p. 10). When Jessica noted that she was "really drawn to the whole idea" and "found kind of a real place" that "keeps pushing and [she] never felt before", it was as if she had found an itch that could not be ignored. Jessica could no longer ignore this "place" she had found magnetically drawing her attention and calling her to attend to the learning 
in a new way. Raylene may have been the most emphatic about the need to learn "from the inside out" and the limitations of focusing solely on intent when she stated that "only understanding it cognitively isn't enough...I don't think it's enough really for anyone to really be effective with it".

The call to be effective with couples and families and attending to a felt sense brought about a variety of changes for research participants. Paying attention to and listening to that call brings our body forward, no longer melted into the horizon of day-to-day life. This occurred partly by participants' own noticing their work in a new way and partly by engaging in a learning and supervision process that involved others. As Finlay noted about being watched by an Other, when "we become aware of their regard we begin to exist in a new bodily self-conscious, unnatural way" ([59], p. 31). Much as one becomes aware of all the things they do with their back when they injure it, how they use it with every movement, every cough, and how they sit or lie down, research participants suddenly became aware of their therapy practice in new and, at times, painful ways. Finlay describes this awareness as "both an altered experience of one's body and an altered experience of the world-and that these are one and the same" ([58], p. 33). This altered experience becomes hard to ignore, as Jessica said, "there's something that's deeper in this and that's what keeps me coming back".

Jessica's call or invitation to return to and pay attention to what she was learning because it was "deeper" suggests an area or a project that now has her attention. Romdenh-Romluc explains this phenomenon by noting that a "perceiver perceives their environment as 'inviting' them to interact in certain ways, as 'offering' certain possibilities for action and 'disallowing' others" ([59], p. 74). A number of the research participants noted how their engagement with learning a new EBP changed as they progressed. Raylene, for example, started out thinking that it would be a few days at a workshop and then realized "you can't go to a weekend training and learn EFT". She went on to emphasize that it had "to do with having the inner experience internally so that you get the experience from the inside out". Raylene noted the opportunity to respond to her felt sense and how it altered her and her therapy world, “deeply, deeply, deeply" affecting both.

Merleau-Ponty, as noted by Romdenh-Romluc [59], suggested that the environment "invites" therapists to engage with their learning in certain ways and disallows others. Gendlin describes this process as a "change [that] begins but seems oddly, mysteriously incomplete. It gives you the start of a shift, but you know (your body knows) a more complete shift is possible" ([65], p. 15). The invitation from the environment that Merleau-Ponty wrote about provides the opportunity for learners to resonate with a felt sense and make meaning of it. Some of the research participants here discussed the challenges with that process both individually and in the environments they worked in. Ken noted that it was "by far the most difficult training and learning process that [he had] ever been in" while George spoke to the challenges he experienced in his work environment and how he managed those. He described how "more and more" of his colleagues were "doing things that can be programmed" as a means to respond to "government" and the "paymasters". George went on to describe his colleagues' efforts to address how government funding was spent by looking to "evidence-based practice". For George this meant a "move" that would allow him to retain and attend to his felt sense about what was effective in his work with families. He described it as follows: "In some ways I have actually moved a little bit outside of mainstream because I'm getting increasingly concerned by that, fiscal restraints on health care and the exclusion of therapies that can't be proven to be effective and the shortness of treatment lengths now which are really driven by cost implications." George's "move" is a means to 
understand and make sense of the push and pull of his environment. The invitations that the environments offer as a means to explore something "deep" or "inside" of the research participants, that opportunity to resonate and make sense, also lead to some of the research participants describing a powerful shift in their bodies.

This powerful shift so aptly described by Ken as feeling like he had "reached Everest on this issue" with regards to integrating a new approach to working with couples was felt in the body by the research participants in this research project. Romdenh-Romluc describes how "the exercise of their skill at something also manifests as understanding of both their surroundings and themselves" ([59], p. 90). Ken not only experiences himself as competent but imbued his description with the exhilaration of accomplishing a long worked for goal and a celebratory environment. Gendlin describes this change process as "natural to the body" ([65], p. 8) with the crucial move that "goes beneath the usual painful places to a bodily sensing that is at first unclear" ([65], p. 8). Much as Ken described, this experience "of something emerging from there feels like a relief and a coming alive" ([65], p. 8). Ken's exhilaration and bodily awareness points to a significance that Merleau-Ponty addressed in his work.

Romdenh-Romluc [59] noted the importance of imbuing environments with motor significance. For couple and family therapists adding a bodily sense of what it is like to be in the kind of relationship or family we are working with, as if we are in it, provides an important source of information. Merleau-Ponty suggests that the body is integral to the understanding of the human situation. He writes, "I perceive in a total way with my whole being; I grasp a unique structure of the thing, a unique way of being, which speaks to all my senses at once" ([74], p. 50). Raylene reflected this way of knowing by stating that “that's what you have to be able to do with clients, and if you can't do that with yourself, you're not going to be able to do that with clients". The participants who felt the exhilaration of knowing "from the inside out" also spoke at length about the pain they experienced along the way to integrating a new EBP. In the end though, it left them with a sense of confidence and knowing, that they felt "in" them. Ken reported that he "[felt] so much more confident, than [he ever had] been". Reaching the peak of Everest will leave one with confidence and an understanding of one self, as Gendlin writes, "there is a kind of bodily awareness that profoundly influences our lives" ([65], p. 32). This shift is what Gendlin referred to as a felt sense.

With attention to a sensation, or a need to learn something new about working with couples and families, a shift begins. Gendlin described how "a felt sense will shift if you approach it in the right way. It will change even as you are making contact with it. When your felt sense of a situation changes, you change..." ([65], p. 32). Paying attention to the body adds to the rational knowledge that is the starting point for learning a new therapy approach. The knowledge that the body adds however, cannot be replaced by rational knowledge. Romdenh-Romluc writes that "one's bodily self knows how to act, and it has a motor understanding of one's surroundings that is not reducible to conceptual knowledge" ([59], p. 102). For the participants here, finding ways to explain how they learned and used an EBP could not be encapsulated by describing an acquisition of knowledge or demonstrating prescribed skill sets. They often used a pre-reflective means of knowing that requires the whole body.

Stoltz noted that the implications of embodied learning are significant because the "phenomenal body" "provides the means through which we can develop a sense of our own identity that is integral to coming to know the world through the experience of our embodiment that has serious ramifications concerning the act of learning" ([56], p. 478). This has implications for therapists learning an EBP and 
for the EBP project in general. Some researchers only have an interest in what can be seen and measured and this approach to research has been applied to embodied learning as well. Kontra, Goldin-Meadow, and Beilock [75], for example, explore embodiment by looking at the impact of movement on learning. While such an objective approach can address part of the implications for embodied learning, couple and family therapists, as reflected by our research participants, would benefit from a more holistic understanding that begins with the understanding that they are their body.

\section{Conclusions}

As researchers, educators, administrators, policy makers, and clinicians struggle with what works best with which populations and when, how best to allocate resources, how best to educate and support clinicians, and the complexity of doing research in real-life settings, this research project has the potential to contribute to those varied dialogues. Integrating an understanding of learning as embodied broadens the traditional rationalist perspective that limits applying a new EBP in a CFT practice to information acquisition and skill practice. While the therapists in this research project reported feeling more effective in their work, further research could explore the experiences that clients have while therapists are learning an EBP as well as any impact on clinical outcomes.

\section{Author Contributions}

This paper is based on the Robert Allan's doctoral dissertation. Primary responsibility for drafting the article was his. Virginia Eatough participated on Robert Allan's thesis committee and contributed to the writing of this paper. Micahel Ungar supervised the thesis and also assisted with the conceptualization and writing of this paper.

\section{Conflicts of Interest}

The authors declare no conflict of interest.

\section{References}

1. John Hunsley. "Addressing Key Challenges in Evidence-Based Practice in Psychology." Professional Psychology Research and Practice 38 (2007): 113-21.

2. Thomas Sexton, Kristina C. Gordon, Alan Gurman, Jay Lebow, Amy Holtzworth-Munroe, and Susan Johnson. "Guidelines for Classifying Evidence-Based Treatments in Couple and Family Therapy." Family Process 50 (2011): 377-92.

3. Douglas H. Sprenkle. "Intervention Research in Couple and Family Therapy: A Methodological and Substantive Review and an Introduction to the Special Issue." Journal of Marital \& Family Therapy 38 (2012): 3-29.

4. Jonathan A. Smith, Paul Flowers, and Michael Larkin. Interpretive Phenomenological Analysis: Theory, Method, and Research. London: Sage, 2009.

5. Michael Ungar. Counseling in Challenging Contexts: Working with Individuals and Families Across Clinical and Community Settings. Belmont: Brooks/Cole, 2011. 
6. Michael Ungar. "The Social Ecological Approach (S.E.A.) to Counseling in Challenging Contexts: Clinicians Manual." Unpublished manuscript, last modified 14 February 2013. Microsoft Word file.

7. Guy S. Diamond, Gary M. Diamond, and Susanne A. Levy. Attachment-Based Family Therapy for Depressed Adolescents. Washington: American Psychological Association, 2013.

8. John M. Gottman. The Marriage Clinic: A Scientifically-Based Marital Therapy. New York: W. W. Norton, 1999.

9. Harville Hendrix. Getting the Love You Want: A Guide For Couples. New York: H. Holt, 1988.

10. Christine E. Ryan, Nathan B. Epstein, Gabor I. Keitner, Ivan W. Miller, and Duane S. Bishop. Evaluating and Treating Families: The McMaster Approach. New York: Routledge, 2005.

11. Leslie S. Greenberg, Cindy L. Ford, Louise S. Alden, and Susan M. Johnson. "In-Session Change in Emotionally Focused Therapy for Couples." Journal of Consulting and Clinical Psychology 61 (1993): 78-84.

12. Susan M. Johnson. The Practice of Emotionally Focused Couple Therapy: Creating Connection. New York: Brunner-Routledge, 2004.

13. Susan M. Johnson, and Leslie S. Greenberg. "Emotionally Focused Marital Therapy: An Overview." Psychotherapy: Theory, Research \& Practice 24 (1987): 552-60.

14. Gregory Bateson. Steps to an Ecology of Mind. St Albans: Paladin, 1973.

15. John Bowlby. Attachment and Loss: Vol. 1. Attachment. New York: Basic Books, 1969.

16. Murray Bowen. Family Therapy in Clinical Practice. New York: Jason Aronson, 1978.

17. Jay Haley. Strategies of Psychotherapy. New York: Grune \& Stratton, 1963.

18. Salvador Minuchin. Families and Family Therapy. Cambridge: Harvard University Press, 1974.

19. Gregory Bateson. Mind and Nature: A Necessary Unity. New York: Dutton, 1979.

20. Michael Anderson. Sociology of the Family: Selected Readings. Harmondsworth: Penguin, 1971.

21. Jessie Bernard. The Future of Marriage. New York: World Publishing, 1972.

22. Philip Blumstein, and Pepper Schwartz. American Couples: Money, Work, Sex. New York: William Morrow and Company, 1983.

23. Ludwig von Bertalanffy. General System Theory: Foundations, Development, Applications. New York: G. Braziller, 1969.

24. Urie Bronfenbrenner. The Ecology of Human Development: Experiments by Nature and Design. Cambridge: Harvard University Press, 1979.

25. Humberto R. Maturana, and Francisco J. Varela. The Tree of Knowledge: The Biological Roots of Human Understanding. Boston: Shambhala, 1992.

26. Ilya Prigogine. "Time, Structure, and Fluctuations.” Science 201 (1978): 777-85.

27. Paul Watzlawick, Janet B. Bavelas, and Don D. Jackson. Pragmatics of Human Communication: A Study of Interactional Patterns, Pathologies, and Paradoxes. New York: Norton, 1967.

28. Lynn Hoffman. Foundations of Family Therapy: A Conceptual Framework for Systems Change. New York: Basic Books, 1981.

29. Michael P. Nichols. Family Therapy: Concepts and Methods. Boston: Allyn \& Bacon, 2010.

30. Douglas H. Sprenkle, Sean D. Davis, and Jay L. Lebow. Common Factors in Couple and Family Therapy: The Overlooked Foundation for Effective Practice. New York: Guilford Press, 2009. 
31. Dennis Balcom. "The Interpersonal Dynamics and Treatment of Dual Trauma Couples." Journal of Marital and Family Therapy 22 (1996): 431-42.

32. Monica McGoldrick, and Kenneth V. Hardy. Revisioning Family Therapy: Race, Culture and Gender in Clinical Practice, 2nd ed. New York: Guilford, 1998.

33. Sherod Miller, Phyllis Miller, Elam W. Nunnally, and Daniel B. Wackman. Talking and Listening Together. Littleton: Interpersonal Communication Program, 1991.

34. American Psychological Association. "Task Force on Promotion and Dissemination of Psychological Procedures, Division of Clinical Psychology, Training in and dissemination of empirically-validated psychological treatments: Report and recommendations." The Clinical Psychologist 48 (1995): 3-23.

35. James F. Alexander, Thomas L. Sexton, and Michael S. Robbins. "The Developmental Status of Family Therapy in Family Psychology Intervention Science.” In Family Psychology Science-Based Interventions. Edited by Howard A. Liddle, Daniel A. Santisteban, Ronald F. Levant and James H. Bray. Washington: American Psychological Association, 2002, pp. 17-40.

36. Martin E. P. Seligman. "The Effectiveness of Psychotherapy: The Consumer Reports Study." American Psychologist 50 (1995): 965-74.

37. Jacqueline B. Persons, and George Silberschatz. "Are Results of Randomized Controlled Trials Useful to Psychotherapists?" Journal of Consulting and Clinical Psychology 66 (1998): 126-35.

38. Nick Midgley. "Editorial: Improvers, Adapters and Rejecters the Link between 'Evidence-Based Practice' and 'Evidence-Based Practitioners'." Clinical Child Psychology and Psychiatry 14 (2009): 323-27.

39. Thomas L. Sexton, and James L. Alexander. "Family-Based Empirically Supported Intervention Programs." The Counseling Psychologist 30 (2002): 238-61.

40. Pedro Morago. "Evidenced-Based Practice: From Medicine to Social Work." European Journal of Social Work 9 (2006): 461-77.

41. Debbie Plath. "Evidenced-Based Practice: Current Issues and Future Directions." Australian Social Work 59 (2006): 56-72.

42. Robert Elliott. "Editor's Introduction: A Guide to the Empirically Supported Treatments Controversy." Psychotherapy Research 8 (1998): 115-25.

43. Dennis Wendt. "The Unevaluated Framework of APA's Policy on Evidence-Based Practice in Psychology (EBPP).” The New School Psychology Bulletin 4 (2006): 89-99.

44. Brent D. Slife, Bradford J. Wiggins, and Jason T. Graham. "Avoiding an EST Monopoly: Toward a Pluralism of Philosophies and Methods." Journal of Contemporary Psychotherapy 35 (2005): 83-97.

45. Kirsti Malterud. "The Art and Science of Clinical Knowledge: Evidence beyond Measures and Numbers." Lancet 358 (2001): 397-400.

46. Jane Gilgun. "Evidence-Based Practice, Descriptive Research and the Resilience-Schema-GenderBrain Functioning (RSGB) Assessment.” British Journal of Social Work 35 (2005): 843-62.

47. Scott D. Miller, Barry L. Duncan, and Mark A. Hubble. "Outcome-Informed Clinical Work." In Handbook of Psychotherapy Integration, 2nd ed. Edited by John C. Norcross and Marvin R. Goldfried. New York: Oxford University Press, 2005, pp. 84-102.

48. Martin E. P. Seligman. "Science as an Ally of Practice." American Psychologist 51 (1996): 1072-79. 
49. Stephen Coulter. "Systemic Family Therapy for Families Who Have Experienced Trauma: A Randomised Controlled Trial.” British Journal of Social Work 41 (2011): 502-19.

50. Karen M. Staller. "Railroads, Runaways \& Researchers: Returning Evidence Rhetoric to its Practice Base.” Qualitative Inquiry 12 (2006): 503-22.

51. William Henry. "Science, Politics, and the Politics of Science: The Use and Misuse of Empirically Validated Treatment Research." Psychotherapy Research 8 (1998): 126-40.

52. Eileen Gambrill. "Evidence-Informed Practice: Antidote to Propaganda in the Helping Professions?" Research on Social Work Practice 20 (2010): 302-20.

53. Martyn Hammersley. "Some Questions about Evidence-Based Practice in Education." In Evidence-Based Practice in Education. Edited by Gary Thomas and Richard Pring. New York: Open University Press, 2004, pp. 133-49.

54. Dave Holmes, Stuart J. Murray, Amélie Perron, and Geneviève Rail. "Deconstructing the Evidence-Based Discourse in Health Sciences: Truth, Power and Fascism." International Journal of Evidence-Based Healthcare 4 (2006): 180-86.

55. Kevin M. Laska, Alan S. Gurman, and Bruce E. Wampold. "Expanding the Lens of Evidence-Based Practice in Psychotherapy: A Common Factors Perspective." Psychotherapy 51 (2013): 467-81.

56. Steven A. Stolz. "Embodied Learning." Educational Philosophy and Theory 47 (2015): 474-87.

57. Maurice Merleau-Ponty. 2005. Phenomenology of Perception. Translated by Colin Smith. London: Routledge. First published 1945.

58. Linda Finlay. Phenomenology for Therapists: Researching the Lived World. Chichester: Wiley-Blackwell, 2011.

59. Komarine Romdenh-Romluc. Routledge Philosophy Guidebook to Merleau-Ponty and Phenomenology of Perception. New York: Routledge, 2011.

60. Paula M. Niedenthal. "Embodying Emotion.” Science 316 (2007): 1002-5.

61. Dermot Moran. Introduction to Phenomenology. London: Routledge, 2000.

62. Linda Finlay. "'Reflexive Embodied Empathy': A Phenomenology of Participant-Researcher Intersubjectivity." The Humanistic Psychologist 33 (2005): 271-92.

63. Paul Ricœur. Freud and Philosophy: An Essay on Interpretation. New Haven: Yale University Press, 1970.

64. Katie Reid, Paul Flowers, and Michael Larkin. "Exploring Lived Experience." The Psychologist 18 (2005): 20-23.

65. Eugene T. Gendlin. Focusing. New York: Everest House, 1978.

66. Oxford Dictionaries. "Viscera." Available online: http://www.oxforddictionaries.com/definition/ english/viscera (accessed on 12 February 2014).

67. Eric Matthews. Merleau-Ponty: A Guide for the Perplexed. London: Continuum, 2006.

68. Oxford Dictionaries. "Primal." Available online: http://www.oxforddictionaries.com/definition/ english/primal (accessed on 12 February 2014).

69. Harry F. Harlow, and Robert R. Zimmermann. "The Development of Affective Responsiveness in Infant Monkeys." Proceedings of the American Philosophical Society 102 (1958): 501-9.

70. Oxford Dictionaries. "Scientist." Available online: http://www.oxforddictionaries.com/definition/ english/artist (accessed on 12 February 2014). 
71. Oxford Dictionaries. "Artist." Available online: http://www.oxforddictionaries.com/definition/ english/artist (accessed on 12 February 2014).

72. Maurice Merleau-Ponty. The Visible and the Invisible. Evanston: Northwestern University Press, 1968.

73. Scott D. Churchill, Julie E. Lowery, Owen McNall, and Aruna Rao. "The Question of Reliability in Interpretive Psychological Research: A Comparison of Three Phenomenologically Based Protocol Analyses." In Phenomenological Inquiry in Psychology: Existential and Transpersonal Dimensions. Edited by Ron Valle. New York: Plenum Press, 1998, pp. 63-85.

74. Maurice Merleau-Ponty. Sense and Non-Sense. Evanston: Northwestern University Press, 1964.

75. Carly Kontra, Susan Goldin-Meadow, and Sian L. Beilock. "Embodied Learning Across the Life Span.” Topics in Cognitive Science 4 (2012): 1-9.

(C) 2015 by the authors; licensee MDPI, Basel, Switzerland. This article is an open access article distributed under the terms and conditions of the Creative Commons Attribution license (http://creativecommons.org/licenses/by/4.0/). 